\title{
BURNOUT IN THE CLINICAL PERSONNEL OF PUERTO RICO DURING THE COVID-19 PANDEMIC
}

Gustavo G. Cortina-Rodríguez ${ }^{1-2}$, Yelianne Afanador ${ }^{3}$

1. University of Puerto Rico, Mayaguez Campus, Psychology Department

2. Director, Quality of Life Office at the University of Puerto Rico, Mayaguez Campus

3. Student of Master's Degree in Counseling Psychology at the Carlos Albizu University Name and address of the corresponding author:

Gustavo G. Cortina-Rodríguez, PhD, FRSPH (https://orcid.org/0000-0003-3442-6774)

University of Puerto Rico, Mayaguez Campus

Mayaguez, PR

Email address: gustavo.cortina@upr.edu 


\section{ABSTRACT}

Objective: To examine the burnout syndrome among the healthcare personnel in Puerto Rico during the COVID-19 pandemic.

Methods: Descriptive study that pursues to understand burnout syndrome in the clinical personnel in Puerto Rico. The Maslach Burnout Inventory (MBI) was sent via email to healthcare professionals around the island. Furthermore, open questions were asked to the participants.

Results: The overall burnout level on the clinical personnel was found to be moderate. Nonetheless, in physicians, $12.1 \%$ had severe burnout levels compared to a $13.1 \%$ score in nurses. Additionally, $92.4 \%$ of physicians and $100 \%$ of nurses had moderate to severe burnout. In the three subscales, nurses scored high levels in all of them, and physicians were high in Emotional Exhaustion and moderate level in Depersonalization and Personal Accomplishment at Work. There were high levels of burnout syndrome of the clinical personnel in Puerto Rico.

Conclusion: Since the beginning of the COVID-19 pandemic, over $90 \%$ of healthcare professionals in Puerto Rico have been working with moderate to severe burnout syndrome, being the nurses the most affected.

Key Words: Burnout syndrome, MBI, Clinical personnel, COVID-19, SARS-CoV-2 


\section{INTRODUCTION}

COVID-19 is a disease produced by the SARS-CoV-2 virus that originated in December 2019, with the first case notified in Wuhan, China. Since then, the outbreak turned into an epidemic and finally into the pandemic that we are still experiencing. [1] In several countries, we have seen an overwhelming situation where the health system cannot cope and has complicated the situation to save lives. However, clinical personnel has had to work long hours and new shifts to mitigate the effects on the health system. For example, we saw countries like China, Spain, Italy, and the United States, where the rate of spread of the disease was high, and the search for health services increased substantially.[2]

Burnout syndrome is a situation that is progressively generated until it often leads to a state of inability to continue with routine work. It usually develops in people whose profession involves a profound dedication to third parties, such as, for example, teaching, health, and social affairs professionals.[3] The consequences of burnout include high absenteeism, the consumption of medicines to fall asleep, substances or drugs, and the adoption of certain dangerous or violent behaviors. Besides, conflicts may appear in the workplace, due to a significant decrease in performance and motivation, as well as in the quality of the services.[4,3]

It is important to remark that burnout is a psychological syndrome that includes emotional exhaustion, depersonalization, and decreased personal achievement. There is an increase in emotional exhaustion and workers feel that they are not capable of concentrating on a psychological level.[5] Another important aspect is the development of depersonalization, which can lead to pessimistic attitudes and feelings to patients. The development of depersonalization seems to be related to the experience of emotional exhaustion. The third important aspect of burnout is the decrease in personal achievement, which is a tendency to evaluate oneself negatively, particularly concerning working with patients.[6]

This disorder has been classified by the World Health Organization (WHO) as a problem related to difficulty in controlling your life, nevertheless now a new classification will appear in the next International Classification of Diseases (ICD-11) as a problem associated with employment or unemployment. According to experts, this change will make this disorder more visible and facilitate the management of sick leave and disabilities. This new classification will is documented to take effect in 2022.[7]

Workers in the first line of defense (physicians, nurses, respiratory therapists, among others) due to their workload, are subject to emotional stress and anxiety; which are directly related to their work.[8] During this pandemic, we have seen the spread of a virus that we do not fully understand, an uprising in deaths among medical personnel and the concern of getting infected in their workspace. Adding those variables, along with a higher patient volume, we can see clinical personnel feeling overwhelmed.[9] The pandemic has caused a general increase in new cases of depression and anxiety and exacerbates existing mental health conditions in health professionals. Limited resources, long working hours, interruptions to sleep, the balance between personal life 
and work, and the occupational risks associated with exposure to COVID-19 have contributed to physical and mental fatigue, stress, anxiety, and burnout.[10]

This investigation was designed to study the burnout in the clinical personnel of the commonwealth of Puerto Rico. To this day, there is no study of this area on the island during this times. Understanding the situation on the island can help develop essential interventions and prevention measures that can be beneficial to the well-being of the people working directly with patients.

\section{METHODS}

This is a descriptive study that pursues to understand burnout syndrome in the clinical personnel in Puerto Rico. An email approach was made to the College of Surgeons of PR, the Nursing Association of Puerto Rico, and direct calls to hospitals to disseminate a questionnaire. The agencies were in charge of sending the questionnaire through email. A non-probabilistic snowball sampling method was used. The questionnaire was accessed in the Zoho platform 465 times. From that total, we received 107 responses, and from those, 96 were valid and accepted to participate in the study. The self-directed survey consisted of four parts: consent form, sociodemographic questionnaire, The Maslach Burnout Inventory (MBI), and open questions directly related to their work and COVID-19. The MBI is a survey whose objective is to determine the presence of the Burnout Syndrome. The MBI includes 22 items evaluated using a Likert scale, which is rated from 0 (never) to 6 (daily), which allows determining the frequency with which the person surveyed presents each of the proposed situations.

The analysis of the 22 items measures three components of the Burnout Syndrome through three subscales: Emotional Exhaustion (EE), Depersonalization (D), and Personal Accomplishment (PA). For EE, a score $>26$ indicates severe emotional exhaustion, from 19 to 26 moderate and $<19$ mild. For D, a score $>9$ indicates severe depersonalization, from 6 to 9 moderate and $<6$ mild. For PA, a score < 34 indicates low personal achievement, moderate from 34 to 39, and > 39 mild. For the global assessment of the scale, a score $>88$ indicates severe Burnout Syndrome, between 44 and 88 moderate and $<44$ is mild.[11]

The results were described globally, including all the personnel participating in the research. The totals on the MBI subscales were then studied in (1) doctors, (2) nurses, (3) any other clinical staff. Groups then individualized the percentage of each scale.

\section{RESULTS}

Responses were received from April 25 to May 25, 2020. Of the respondents, 66 were physicians (68.8\%), 23 nurses (24\%), and 7 with various professions that could include: paramedics, respiratory therapists, among others (7.2\%). Most of the respondents were female, with $57.3 \%$ versus $42.7 \%$ male. The complete sample was calculated to know the total MBI that turned out to have a mean of (70.4) with a standard deviation (SD) of (15.7). If we look at the MBI scale, the overall burnout level on the clinical personnel was moderate (between 44 and 88). Nonetheless, 
in physicians, $12.1 \%$ had severe burnout levels compared to $13.1 \%$ to nurses. Additionally, $92.4 \%$ of physicians and $100 \%$ of nurses had moderate to severe burnout.

The medical personnel's results in the subscales of the $\mathrm{MBI}$, the doctors on the Emotional Exhaustion scale, presented a mean of 27.17 , which is considered high. In Depersonalization, the result was 6.61 were the result is considered moderate. Besides, on the Personal Accomplishment, they had a result of 35.87, which is moderate. The results for nurses in the Emotional Exhaustion were 32 (high), Depersonalization was 9.82 (high), and Personal Achievement at Work 32.71, which shows low personal achievement. For clinical personnel who were not doctors or nurses on the emotional fatigue scale (24.43), which is medium, for Depersonalization, it was (6.73), and that of personal achievement was (33), which is a high level.

In the Emotional Exhaustion subscale, the percentage of the total population showed that $21.9 \%$ was low, 19.8\% moderate, and 58.3\% high burnout syndrome. The results showed that $45.8 \%$ was low, $25 \%$ moderate, and $29.2 \%$ high burnout syndrome in the Depersonalization subscale. The Personal Accomplishment results at Work subscale were $39.1 \%$ for low personal achievement, $35.4 \%$ for moderate personal achievement, and $25 \%$ showing high personal achievement.

\section{Division of Subscales in percentages}

On the Emotional Exhaustion subscale results for physicians, 25.8\% were low, 18.2 moderate, and $56.1 \%$ high. Among the nurses, $13 \%$ were low, $17.4 \%$ moderate, and $69.6 \%$ high. The rest of the clinical person was $14.3 \%$ low, $57.1 \%$ moderate, and $28.6 \%$ high. In the depersonalization subscale results for physicians, $51.5 \%$ were low, $22.7 \%$ moderate, and $25.8 \%$ high. Among the nurses, $21.8 \%$ were low, $39.1 \%$ moderate, and $39.1 \%$ scored high. The rest of the clinical personnel were $71.4 \%$ low, none at the moderate level, and $28.6 \%$ high. As for Personal Accomplishment, physicians were 31.8\% low, 37.9\% moderate, and 30.3\% high. Among nurses, $52.2 \%$ were low, $34.8 \%$ moderate, and $13 \%$ high. For the other clinical personnel, $57.1 \%$ were low, $28.6 \%$ moderate, and $14.3 \%$ high.

\section{Some open questions answers}

We asked three open questions for the health professionals to answer. The first question we asked was: do you think that Puerto Rico has a comprehensive plan for the mental health of health professionals?

Some of the answers exposed were:

- "No, the health professional is marginalized in our country."

- "No, there must be more guidance. In addition to stopping the stigma."

- "Never in my years of experience have I had an employer who is interested in my mental health, they just want you to work without caring about anything." 
- $\quad$ "It does not seem to me that there is a plan to take care of the mental health of health professionals. There is no plan, and health professionals are not considered to experience burnout or mental health problems."

- "No, people think health professionals do not have the right to suffer any pathology, least of all a mental one, which they use to discredit or excuse to censor the professional."

- "Definitely not! We are human beings who suffer and get depressed because of everything we see on a daily basis, but it is wrong for us to seek help for it and they quickly label us as if we could not work for it."

- "There is no plan. I think there may be retaliation if I seek mental help."

The second open question asked was: what has been the most emotional or challenging of this pandemic?

- "Seeing the patient sick alone, without family members."

- "One of the strongest things is knowing that all those hospitalized patients are totally isolated from their relatives. It is also emotionally strong to know that there are people who are not receiving financial aid from the government."

- "Not being able to see my family often and not being able to hug them. See the same situation in my colleagues."

- "Having to go out day by day and think that at any moment I can expose myself unknowingly and infect myself and spread it to my family."

- "Social distancing, although it is effective and key to controlling the pandemic; at the same time it limits providing the necessary screening services."

- "The fear of people, patients and doctors, of getting infected and do not know what to expect."

The third question that was asked was: do you consider that the mental health of professionals is something that the population is aware of?

- "Nobody is aware of the work we do, starting with the mediocre treatment that the bosses and patients give us."

- "They do not believe that because we have chosen this profession, they don't see us as humans, that we have families and that we are also afraid in this environment."

- $\quad$ The population is not aware that health professionals suffer from physical health problems, much less mental health issues since they see us as people who do not have any problem"

- No, they are not aware of that. Many times they treat us as if we are not a human being like them."

- No. We are only a few doing the work of 2 or 3 doctors. Insurers increasingly are taking more away from us and nobody does anything about it. More doctors will continue to leave the island to the US.

- $\quad$ They are not aware. Education in general is very poor in PR. I don't think they read about it. I haven't read about this topic in the newspaper, so I don't see how you can know about it." 


\section{DISCUSSION}

The effects of the pandemic can be seen in people all over the world. Those effects are noticeable in the psychical and mental health of the population. For healthcare workers, that is no exception. The sudden change or notion that healthcare workers can turn into patients at any given time, is intimidating.[12] Early investigations in the pandemic show that healthcare workers experience exceptional pressure, tension, sadness, and a sleeping disorder because of the COVID-19.[13] Additionally, increased levels of stress and anxiety have been seen in healthcare workers because there is an absence of direct treatment or immunization. But we do have to mention that contrasted with the episode of SARS, broad media inclusion is prompting stories and to better understand the population under study.[14] Studies directed at the hour of the SARS episode also indicated that crisis division staff are at more danger of creating Post-traumatic stress disorder. This is an area that needs to be addressed and investigated worldwide, especially in countries where hospitals have been overwhelmed. [15]

A systematic survey showed the impact of social help and the effect on the mental wellbeing of the health care workers. According to the report, the primary hazard factors that could develop disorders were all created from lack of adequate training, proper communication, and absence of social or emotional support.[16] In the literature is shown that the impact of social help on selfadequacy, sleep deprivation, tension, and unhappiness is noticeable in past research.[17]

During the pandemic, the focal point of specialists is staying in the natural and physical spaces of the population, disregarding the neglected mental needs. To deal with these psychological issues, the Chinese government, for example, took specific initiatives to handle it. They gave crisis psychiatric emergency intervention for individuals exposed to COVID-19.[18] The government correspondingly used some strategies to deal with the psychological burdens the workers were facing. To achieve this, it had to build up mental institutions, setting work routines like shifts and giving people advice on different platforms.[19] It is essential to develop intervention models that include all the dimensions of health and prepare to work effectively in the near future with all the mental health situations the pandemic is creating.[20]

If we look at our results globally, the result of our study showed that the mean of the MBI was 70.40 , with an SD of 15.70 , scores for a moderate level,. The percentages of high levels of burnout on the subscales were: Emotional Exhaustion (58.3\%), Depersonalization (29.2\%) and in Personal Accomplishment (39.6\%). In physicians, 12.1\% had severe burnout levels compared to $13.1 \%$ to nurses. Additionally, $92.4 \%$ of physicians and $100 \%$ of nurses had moderate to severe burnout. Puerto Rico had proper measures to control the pandemic, but openings without complying with protocols are raising the cases on the island. The study was done at a time when there was no overwhelmed health system.

In the open questions, we saw that health professionals think they are dehumanized and are being seeing differently by their employers and the general population. The answers show they have a perception, that people do not care about them because they not believed to suffer mental health problems. As for the emotional effect during the pandemic, not being able to be with their 
family and fear for them or others, were the most common answers. Government protocols and public policy must be developed to support personnel in the first line of defense since a substantial increase in cases, can deepen this existing exhaustion.

\section{CONCLUSION}

During the COVID-19 pandemic, health professionals in Puerto Rico have been exposed to high levels of stress in the workplace, which caused $58.3 \%$ of them to have high levels of Emotional Exhaustion. In general terms, nurses had high levels of burnout syndrome in the three subscales. Physicians had high to moderate levels in the subscales. It is necessary to implement psychological support measures for health personnel in emergency situations and prepare a thoughtful plan to address the issue for future circumstances.

\section{LIMITATIONS}

A more comprehensive sample and probabilistic study should be conducted to determine other essential variables not taken to consideration in the study. Although over 400 participants accessed the questionnaire, only 96 valid responses were used for the results.

\section{ACKNOWLEDGMENTS}

We gratefully acknowledge the support of all study participants.

\section{CONFLICTS OF INTERESTS}

The other authors have no conflicts of interest.

\section{EXTERNAL FUNDING}

The authors have solved the realization of this article with self-financing. We declare that we have no conflict of interest.

\section{AUTHOR CONTRIBUTION}

All authors made similar contribution. 


\section{REFERENCES}

[1] J. S. Mackenzie and D. W. Smith, "COVID-19: a novel zoonotic disease caused by a coronavirus from China: what we know and what we don't," Microbiol. Aust., Mar. 2020, doi: 10.1071/MA20013.

[2] Q. Liu et al., "The experiences of health-care providers during the COVID-19 crisis in China: a qualitative study," Lancet Glob. Health, vol. 8, no. 6, pp. e790-e798, Jun. 2020, doi: 10.1016/S2214-109X(20)30204-7.

[3] C. Maslach and M. P. Leiter, "Understanding the burnout experience: recent research and its implications for psychiatry," World Psychiatry, vol. 15, no. 2, pp. 103-111, Jun. 2016, doi: 10.1002/wps.20311.

[4] "Burnout Research: Emergence and Scientific Investigation of a Contested Diagnosis Linda V. Heinemann, Torsten Heinemann, 2017." https://journals.sagepub.com/doi/full/10.1177/2158244017697154 (accessed Jul. 18, 2020).

[5] K. Bauernhofer et al., "Subtypes in clinical burnout patients enrolled in an employee rehabilitation program: differences in burnout profiles, depression, and recovery/resourcesstress balance," BMC Psychiatry, vol. 18, Jan. 2018, doi: 10.1186/s12888-018-1589-y.

[6] C. Maslach and S. E. Jackson, "The measurement of experienced burnout," J. Organ. Behav., vol. 2, no. 2, pp. 99-113, Apr. 1981, doi: 10.1002/job.4030020205.

[7] "WHO | Burn-out an 'occupational phenomenon': International Classification of Diseases," WHO. http://www.who.int/mental_health/evidence/burn-out/en/ (accessed Jul. 17, 2020).

[8] H. Blake, F. Bermingham, G. Johnson, and A. Tabner, "Mitigating the Psychological Impact of COVID-19 on Healthcare Workers: A Digital Learning Package," Int. J. Environ. Res. Public. Health, vol. 17, no. 9, May 2020, doi: 10.3390/ijerph17092997.

[9] N. Sun et al., "A qualitative study on the psychological experience of caregivers of COVID19 patients," Am. J. Infect. Control, vol. 48, no. 6, pp. 592-598, Jun. 2020, doi: 10.1016/j.ajic.2020.03.018.

[10] N. Restauri and A. D. Sheridan, "Burnout and Posttraumatic Stress Disorder in the Coronavirus Disease 2019 (COVID-19) Pandemic: Intersection, Impact, and Interventions," J. Am. Coll. Radiol., vol. 17, no. 7, pp. 921-926, Jul. 2020, doi: 10.1016/j.jacr.2020.05.021.

[11] W. Schaufeli, K. Hoogduin, C. Schaap, and A. Kladler, "On the clinical validity of the Maslach Burnout Inventory and the Burnout Measure," Psychol. Health, vol. 16, pp. 56582, Sep. 2001, doi: 10.1080/08870440108405527.

[12] S. Dubey et al., "Psychosocial impact of COVID-19," Diabetes Metab. Syndr., vol. 14, no. 5, pp. 779-788, 2020, doi: 10.1016/j.dsx.2020.05.035.

[13] N. Titov et al., "Rapid report: Early demand, profiles and concerns of mental health users during the coronavirus (COVID-19) pandemic," Internet Interv., vol. 21, p. 100327, Sep. 2020, doi: 10.1016/j.invent.2020.100327.

[14] A. Chevance et al., "Ensuring mental health care during the SARS-CoV-2 epidemic in France: A narrative review," L'Encephale, vol. 46, no. 3, pp. 193-201, Jun. 2020, doi: 10.1016/j.encep.2020.04.005.

[15] I. W. C. Mak, C. M. Chu, P. C. Pan, M. G. C. Yiu, S. C. Ho, and V. L. Chan, "Risk factors for chronic post-traumatic stress disorder (PTSD) in SARS survivors," Gen. Hosp. Psychiatry, vol. 32, no. 6, pp. 590-598, 2010, doi: 10.1016/j.genhosppsych.2010.07.007.

[16] "A Systematic Review of the Impact of Disaster on the Mental Health of Medical Responders | Prehospital and Disaster Medicine | Cambridge Core." https://www.cambridge.org/core/journals/prehospital-and-disastermedicine/article/systematic-review-of-the-impact-of-disaster-on-the-mental-health-ofmedical-responders/3E47050C408ECAC563C24F0276DEE947 (accessed Jul. 17, 2020). 
[17] H. Xiao, Y. Zhang, D. Kong, S. Li, and N. Yang, "Social Capital and Sleep Quality in Individuals Who Self-Isolated for 14 Days During the Coronavirus Disease 2019 (COVID19) Outbreak in January 2020 in China," Med. Sci. Monit. Int. Med. J. Exp. Clin. Res., vol. 26, pp. e923921-1-e923921-8, Mar. 2020, doi: 10.12659/MSM.923921.

[18] W. Li et al., "Progression of Mental Health Services during the COVID-19 Outbreak in China," Int. J. Biol. Sci., vol. 16, no. 10, pp. 1732-1738, Mar. 2020, doi: $10.7150 / i j b s .45120$.

[19] L. Kang et al., "The mental health of medical workers in Wuhan, China dealing with the 2019 novel coronavirus," Lancet Psychiatry, vol. 7, no. 3, p. e14, 2020, doi: 10.1016/S2215-0366(20)30047-X.

[20] M. S. Wolf et al., "Awareness, Attitudes, and Actions Related to COVID-19 Among Adults With Chronic Conditions at the Onset of the U.S. Outbreak," Ann. Intern. Med., Apr. 2020, doi: 10.7326/M20-1239. 


\section{TABLES}

Table 1. MBI Average Score by Profession in Subscales

\begin{tabular}{lccc}
\hline Professions & $\begin{array}{c}\text { Emotional } \\
\text { Exhaustion }\end{array}$ & Depersonalization & $\begin{array}{c}\text { Personal } \\
\text { Accomplishment }\end{array}$ \\
\hline $\begin{array}{l}\text { Physicians } \\
\mathrm{n}=66\end{array}$ & $\begin{array}{c}27.17 \\
\text { (High) }\end{array}$ & $\begin{array}{c}6.61 \\
\text { (Medium) }\end{array}$ & $\begin{array}{c}35.87 \\
\text { (Medium) }\end{array}$ \\
$\begin{array}{l}\text { Nurses } \\
\mathrm{n}=23\end{array}$ & $\begin{array}{c}32 \\
\text { (High) }\end{array}$ & $\begin{array}{c}9.82 \\
\text { (High) }\end{array}$ & 32.71 \\
$\begin{array}{l}\text { Others } \\
\mathrm{n}=7\end{array}$ & $\begin{array}{c}24.43 \\
\text { (Medium) }\end{array}$ & $\begin{array}{c}6.73 \\
\text { (Medium) }\end{array}$ & 33 \\
\hline
\end{tabular}


Table 2. Percentage by profession in MBI subscales

\begin{tabular}{|c|c|c|c|c|}
\hline Profession &. & $\begin{array}{l}\text { Emotional } \\
\text { Exhaustion }\end{array}$ & Depersonalization & $\begin{array}{l}\text { Personal } \\
\text { Accomplishment }\end{array}$ \\
\hline \multicolumn{5}{|l|}{$\begin{array}{l}\text { Physicians } \\
n=66\end{array}$} \\
\hline & Low & $\begin{array}{l}25.8 \% \\
(17 / 66)\end{array}$ & $\begin{array}{l}51.5 \% \\
(34 / 66)\end{array}$ & $\begin{array}{l}31.8 \% \\
(21 / 66)\end{array}$ \\
\hline & Medium & $\begin{array}{r}18.2 \% \\
(12 / 66)\end{array}$ & $\begin{array}{l}22.7 \% \\
(15 / 66)\end{array}$ & $\begin{array}{l}37.9 \% \\
(25 / 66)\end{array}$ \\
\hline & High & $\begin{array}{r}56.1 \% \\
(37 / 66)\end{array}$ & $\begin{array}{l}25.8 \% \\
(17 / 66)\end{array}$ & $\begin{array}{l}30.3 \% \\
(20 / 66)\end{array}$ \\
\hline \multicolumn{5}{|l|}{$\begin{array}{l}\text { Nurses } \\
n=23\end{array}$} \\
\hline & Low & $\begin{array}{l}13.0 \% \\
(3 / 23)\end{array}$ & $\begin{array}{l}21.8 \% \\
(5 / 23)\end{array}$ & $\begin{array}{l}52.2 \% \\
(12 / 23)\end{array}$ \\
\hline & Medium & $\begin{array}{l}17.4 \% \\
(4 / 23)\end{array}$ & $\begin{array}{l}39.1 \% \\
(9 / 23)\end{array}$ & $\begin{array}{l}34.8 \% \\
(8 / 23)\end{array}$ \\
\hline & High & $\begin{array}{l}69.6 \% \\
(16 / 23)\end{array}$ & $\begin{array}{l}39.1 \% \\
(9 / 23)\end{array}$ & $\begin{array}{l}13 \% \\
(3 / 23)\end{array}$ \\
\hline \multicolumn{5}{|l|}{$\begin{array}{l}\text { Others } \\
n=7\end{array}$} \\
\hline & Low & $14.3 \%$ & $71.4 \%$ & $57.1 \%$ \\
\hline & & $(1 / 7)$ & $(5 / 7)$ & $(4 / 7)$ \\
\hline & Medium & $\begin{array}{l}57.1 \% \\
(4 / 7)\end{array}$ & $\begin{array}{l}0 \% \\
(0 / 7)\end{array}$ & $\begin{array}{l}28.6 \% \\
(2 / 7)\end{array}$ \\
\hline & High & $28.6 \%$ & $28.6 \%$ & $14.3 \%$ \\
\hline & & $(2 / 7)$ & $(2 / 7)$ & $(1 / 7)$ \\
\hline
\end{tabular}


Table 3. MBI Average Score of Total Population in Subscales

\begin{tabular}{llll}
$\begin{array}{l}\text { Total Population } \\
\mathbf{N}=96\end{array}$ & $\begin{array}{l}\text { Emotional } \\
\text { Exhaustion }\end{array}$ & Depersonalization & $\begin{array}{l}\text { Personal } \\
\text { Accomplishment }\end{array}$ \\
\hline & 28.12 & 7.38 & 34.86 \\
& High & Medium & Medium \\
\hline
\end{tabular}

Table 4. Percentages in Total Population on the MBI Subscales

\begin{tabular}{llll}
\hline $\begin{array}{l}\text { Total Population } \\
\text { N=96 }\end{array}$ & $\begin{array}{l}\text { Emotional } \\
\text { Exhaustion }\end{array}$ & Depersonalization & $\begin{array}{l}\text { Personal } \\
\text { Accomplishment }\end{array}$ \\
\hline Low & $21.9 \%$ & $45.8 \%$ & $39.6 \%$ \\
& $(0-18) 21 / 96$ & $(0-5) 44 / 96$ & $(0-33) 38 / 96$ \\
Medium & $19.8 \%$ & $25 \%$ & $35.4 \%$ \\
& $(19-26) 19 / 96$ & $(6-9) 24 / 96$ & $(34-39) 34 / 96$ \\
High & $58.3 \%$ & $29.2 \%$ & $25 \%$ \\
& $(27-54) 56 / 96$ & $(10 / 30) 28 / 96$ & $(40-56) 24 / 96$ \\
\hline
\end{tabular}

